
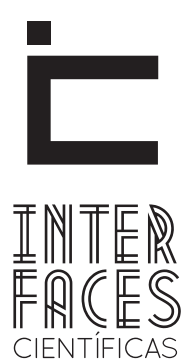

EDUCAÇÃO

ISSN IMPRESSO 2316-333X

ISSN ELETRÔNICO 2316-3828

DOI 10.17564/2316-3828.2015v3n3p67-76

\title{
A PRESENÇA INDÍGENA NOS LIVROS DIDÁTICOS DE HISTÓRIA DO PARANÁ [2000-2011]
}

Mariangela Küller Boiano ${ }^{1}$

\section{RESUMO}

A temática indígena é trabalhada em sala de aula, por meio dos livros didáticos, e é com este material e o auxílio de seus professores, que os alunos conseguem conhecer e compreender não só aquilo que se refere à história indígena, mas todos os outros temas relacionados com a história. 0 interesse pela temática indígena nos livros didáticos leva à reflexão acerca dos conteúdos presentes nestes materiais e analisá-los
Oseias de Oliveira ${ }^{2}$

significa pensar nas maneiras como o indígena vem sendo abordado, e na forma como as leituras contidas nestes livros podem ser compreendidas.

\section{PALAVRAS-CHAVE}

Indígenas. Livros Didáticos. História do Paraná. Irati. 


\section{ABSTRACT}

The Indian theme is crafted in the classroom, through textbooks, and it is with this material and the help of their teachers, students can know and understand not only what refers to the indigenous history, but all other topics related with the story. The interest in indigenous issues in textbooks leads to reflection on the content present in these materials and analyze

\section{RESUMEN}

El tema es indígena artesanal en la sala de clase, a través de libros de enseñanza, y es con este material y la ayuda de sus profesores, los estudiantes pueden conocer y entender no sólo lo que se refiere a la historia indígena, pero todos los otros temas relacionado con la historia. El interés en las cuestiones indígenas en los libros de texto lleva a la reflexión sobre el contenido presente en estos materiales y analizar que them means thinking in ways that indigenous is being addressed, and how the readings contained in these books can be understood.

\section{KEYWORDS}

Indigenous. Textbooks. History of Parana. Irati. significa pensar en formas que los indígenas se ha acercado, y cómo las lecturas de los libros citados se puede entender.

\section{PALAVRAS-CLAVE}

Indígena. Los libros de Texto. Historia del Estado del Paraná. Irati. 


\section{INTRODUCÇÃO}

Este trabalho apresenta uma discussão sobre a presença indígena nos livros didáticos de História do Paraná, destacando a maneira com que os mesmos foram representados nestas produções, tomando como objeto de estudo as obras didáticas escritas entre 2000 e 2011. A narrativa é construída a partir da análise dos livros utilizados nas escolas de ensino fundamental na cidade de Irati/ PR, no período estudado.

Refletir sobre esta temática é importante por permitir analisar a produção e os enfoques da mesma, sendo possível, ainda, problematizar a forma com que o indígena é representado e compreendido pelos alunos que têm acesso às leituras. A investigação que toma como base os livros didáticos permite a compreensão de que:

O livro didático é um objeto de pesquisa importante na História da Educação, pois ele acompanha os alunos em todas as fases da aprendizagem, é portanto de uma memória nacional, possui um valor cultural e merece todo o nosso respeito, porém, não vem recebendo um tratamento adequado. (MARIANO, 2006, p. 21).

Assim, a pesquisa com livros didáticos, diz muito a respeito da cultura, e do jeito de ser de uma sociedade; a análise, desse material, pode demonstrar as prioridades que são tomadas para com certos assuntos, em detrimento de outros; pode-se, ainda, notar a construção da escrita, a escolha dos conteúdos, que variam de tempos em tempos de acordo com as mudanças culturais e de pensamentos.

Como ressalta Mariano (2006, p. 21) o livro didático é uma importante fonte de pesquisa, pois:

\footnotetext{
Podemos perceber que o livro didático constitui uma fonte privilegiada de pesquisa, porém, é pouco valorizado pela nossa sociedade, é um objetivo visto como segunda categoria que tem um uso efêmero, pois é destinado a uma determinada série e por determinado período letivo, o que acarreta um processo seletivo e seu consequente descarte.
}

A autora destaca a importância do livro didático como fonte de pesquisa, enfatizando que embora tais produções sejam compreendidas de forma limitada, como algo para uma série específica, algo passageiro, é de fundamental importância para a história da educação e deve ser mais valorizada.

O fato de o livro didático ser escrito para uma fase em específico não justifica o olhar de desvalorização que muitas vezes ocorre com relação a ele. Na sua utilização como fonte de reflexão deve-se considerar que esse material é produzido por meio de pesquisas, problematizações, enfoques e é um livro de história como todos os outros, com certos enfoques, prioridades e perspectivas diferenciados que o autor adota.

No que se refere à temática indígena, é frequente a crítica aos livros didáticos que apresentam uma história fragmentada, como se os indígenas estivessem fora da realidade, não habitando mais o país após o descobrimento. Assim, o "desaparecimento" dos indígenas de vários períodos importantes da história do Brasil, acaba legitimando aos alunos a descontextualização destes povos da história do país e a sua "pouca" presença e atuação social ao longo dos tempos.

Então,
As abordagens feitas a partir destes materiais levam os alunos a concluírem que os povos indígenas não fazem parte da sociedade atual, e que estas relações só se deram na época da chegada dos europeus ao Brasil, principalmente porque esse assunto aparece nos livros somente quando abordado este período específico da História do Brasil, não apresentando a participação indígena nos períodos posteriores, denominados ainda como Império e República, man- tendo-os desconectados da história recente do país. (CAVALHEIRO; COSTA, 2012, p. 4).

No entanto, esta visão descontextualizada, e que traz o indígena como integrante de um passado distante, fora da participação na sociedade, é combatida pelos estudiosos do tema na atualidade, assim: 
É justamente esta noção, a de que as sociedades indígenas seriam "evanescentes", isto é destinadas a desaparecer (vanishing people), que tem sido criticada na atualidade. Antes disto, porém, ela influenciou fortemente a política dos estados (tanto coloniais quanto independentes) com suas comunidades indígenas, quase sempre pautada na noção da "transitoriedade" da condição indígena e na proposição de politicas assimilatórias. Assim a legislação acerca dos índios tratou de buscar a sua civilização e inserção na comunidade (cristã e depois nacional), num trabalho para o qual foram mobilizados os agentes da igreja e, a seu tempo, dos estados republicanos. (MARTINS, 2009, p. 156).

Desta forma, percebe-se que muitas das concepções equivocadas veiculadas nas escolas por meio dos livros didáticos acerca dos indígenas, se refletem na realidade social que desde o princípio tentou sobrepor a cultura europeia à indígena, a fim de "civilizar" estes povos, torná-los cristãos e indivíduos integrantes de uma sociedade ao cujo modelo não se enquadrava devido a sua cultura, suas prioridades, aos seus modos de vida que eram distintos dos demais.

Muitos livros didáticos apresentaram ao longo da história um indígena retratado a partir do olhar do conquistador, e é essa a história do Brasil que se encontra nas muitas obras direcionadas à educação escolar. Isso se deve, porque a cultura indígena possui em seus costumes a tradição oral como transmissão de conhecimentos, o que não ocorre com a forma europeia de aprendizado, a qual valoriza de forma mais acentuada a tradição escrita (MARCOS, 2011, p. 2-3).

Portanto, o modo com que cada cultura trabalha com a escrita, acabou se refletindo, também, na construção da sua história. A preocupação em abordar o conteúdo dos livros didáticos utilizados nas escolas consiste na necessidade de refletir sobre como a história indígena vem sendo tratada e quem a escreve. Investigar quais os enfoques e de que indígena o livro fala, se realmente o foco ainda persiste no indígena como um ser do passado que cai no esquecimento, ou se é possível percebê-lo no contexto social atual.

É preciso problematizar o livro didático, sua escrita, suas falas, suas fugas, os "porquês", a ausência e a presença dos indígenas neste material. Este trabalho se justifica, por buscar a crítica dos conteúdos presentes nos livros, a fim de perceber o que os alunos podem aprender com o uso destas fontes e qual a ideia de indígena que se pretende transmitir aos discentes.

\section{INDÍGENA “GENÉRICO”}

A abordagem indígena no livro didático permite discutir, as formas, a presença, e as prioridades relacionadas ao tema que estão contidas nestes textos. Pensar essa questão nos leva a considerar muitos aspectos e chamar a atenção para a cultura, o indígena ontem e hoje, o lugar social do indígena e a compreensão que este material proporciona aos alunos.

Para Grupioni (2001, p. 10), “O Brasil ainda não conhece a realidade indígena, e sabe muito pouco a respeito dos índios e de suas sociedades, suas histórias e seus modos de vida. São muitas as ideias equivocadas a eles associadas". Desta forma, as concepções sobre as etnias indígenas são, muitas vezes marcadas por desconhecimento da realidade cultural, destes povos, e preconceito para com o seu modo de vida.

A imagem de um índio genérico, que vive nu na mata, mora em ocas e tabas, cultua Tupã e Jaci e fala tupi ainda predomina no senso comum. É também muito comum a ideia de que os índios viviam em paz entre si e em harmonia com a natureza até a chegada dos portugueses, em 1500, quando começou um processo de extermínio que resultou no desaparecimento de muitos povos; os sobreviventes estariam se aculturando ou deixando de ser índios. (GRUPIONI, 2001, p. 11).

Embora muito tenha mudado, quando se fala em assistências, em direito para os povos indígenas, em respeito para com estas sociedades e sua história, ainda existe uma ideia de que o indígena só é indígena 
se morar na floresta, se não possuir nenhum contato com a cultura não índia, e, portanto, se não utilizar roupas ou equipamentos tecnológicos.

Quando se fala em índio parece que são todos iguais, que é tudo "uma coisa só", mas, o autor chama a atenção para a existência de muitas etnias e da necessidade de pensar o indígena dentro da sua cultura e do meio em que vive.

A generalização que ocorre se deve, principalmente, porque muitos desconhecem o sentido do termo índio. Ao abordar a respeito das polêmicas, envolvendo o uso e sentidos do termo “índio”, Grupioni (2001, p. 12) ressalta que:

[...] na realidade, o termo "índio" é definido em oposição a "branco". 0 índio genérico não existe: existem povos distintos, com identidades próprias. Existem os Bororó, os Pataxó, os Sateré-Mawé e muitos outros grupos, cada um com seu próprio modo de ser e com sua maneira de ver o mundo.

Portanto, não existe o índio, mas sim povos indígenas, cada um com seus costumes, suas crenças, sua cultura. Quando estes povos são pensados de forma genérica e homogênea, a riqueza das suas culturas se perde e a abordagem da sua história torna-se incompleta.

\section{INDÍGENA DO LIVRO DIDÁTICO}

Mas, a reflexão aqui proposta consiste na abordagem do indígena no livro didático, e o que se percebe é que esta possui algumas características semelhantes quando se analisa o conteúdo destes manuais. Nas palavras de Grupioni, (2001, p. 15): “[...] a história é abordada como se não fosse algo em progresso, que acumula e se transforma, mas sim algo estanque, mascado pelos eventos significativos de uma historiografia basicamente europeia".

O autor complementa destacando que a abordagem dos livros didáticos no que se refere a índios e negros é concentrada no passado, tendo tais personagens como se fossem subordinados ao colonizador (GRUPIONI, 2001, p. 15). Compete-nos indagar a razão pela qual esse discurso é preservado e perceber que se trata de um discurso ordenador, que cria uma ordem de categorias hierarquizantes aplicadas aos indivíduos em sociedade.

Algo que também pode ser frequentemente percebido é o "desaparecimento" social do indígena. Muitos são os materiais didáticos que abordam os indígenas no início da colonização, destacando a grande mortalidade e os momentos trágicos de exploração que estes sofreram, e então os mesmos “desaparecem” da história.

Outra abordagem, constantemente presente nestes materiais, é o índio retratado no seu passado, o morador da aldeia na floresta, caçador e coletor e, no que se refere a isso, Grupioni chama a atenção para a compreensão limitada que pode ocorrer sobre os mesmos, pois:

\begin{abstract}
Ao jogar os índios no passado, os livros didáticos não preparam os alunos para entender a presença indígena no presente e no futuro, apesar de os meios de comunicação divulgarem cotidianamente informações acerca dos índios de hoje. (GRUPIONI, 2001, p. 17).
\end{abstract}

A abordagem demasiadamente repousada no passado faz com que o aluno não consiga perceber o indígena na atualidade como integrante e atuante da sociedade. Mota e Rodrigues destacam a superficialidade com que alguns livros tratam a temática indígena, em que:

Os autores apresentam algumas características gerais dos grupos indígenas brasileiros. Mencionam que existem diferenças entre os grupos mas não avançam no sentido de apontar para algumas que sejam capazes de remeter o leitor às especificidades e singularidades dos grupos [...]. (MOTA; RODRIGUES, 1999, p. 50).

Os autores consideram que a temática indígena deveria trazer maiores esclarecimentos aos alunos, visto que os conteúdos dos livros didáticos são por ve- 
zes superficiais, apresentando o indígena em características gerais, sem considerar suas especificidades.

Outro aspecto presenciado nos livros didáticos é a ideia de bom e mau selvagem, como destaca Grupioni (APUD ALMEIDA, 1987):

A solução apresentada por vários livros didáticos parece ser a de que, na história do Brasil, este índio bom contribuiu para a colonização e deixou traços culturais para a nossa nacionalidade. Mas esse índio acabou por desaparecer. Já o índio mau, o índio problema, esse é o que ainda ocupa espaços e que atrapalha o desenvolvimento.

Existem muitos textos que destacam a "passividade" dos indígenas diante da colonização, o bom selvagem que procurou fazer amizade com o colonizador e que faz parte da mescla de raças existente no país. No entanto, como pontua o autor, este mesmo indígena é percebido como empecilho, o lado mau do selvagem, uma barreira para a contribuição e integração a sociedade capitalista.

Muitas pessoas não conseguem entender o porquê de o indígena reivindicar sua terra, seus direitos, sua cultura; parece que o fato destes defenderem o seu modo de vida, e deste modo diferir das concepções de uma parcela da sociedade, se torna algo inaceitável, incabível na realidade social baseada nas tecnologias e no lucro.

A partir destas observações se torna possível efetuar uma abordagem por meio do livro didático considerando um olhar crítico sobre os povos indígenas do passado e as representações que são feitas dos mesmos no presente, procurando identificar as imagens destes povos nestas obras.

\section{HISTÓRIA DA ESCRITA E DA LEITURA PARA O ESTUDO DAS REPRESENTACÕ̃ES}

Quando se fala em produção escrita, algo que deve ser considerado é a intenção desta escrita, tudo é pro- duzido com uma finalidade, para alguém e tem uma razão de ser. 0 que se escreve, certamente será lido por alguém que não o próprio autor, e por isso:

[...] Antes de mais nada, dar à leitura o estatuto de uma prática criadora, inventiva, produtora e não anulá-la no texto lido, como se o sentido desejado por seu autor devesse inscrever-se com toda a imediatez e transparência, sem resistência nem desvio, no espírito de seus leitores. Em seguida, pensar que os atos de leitura que dão aos textos significações plurais e móveis situam-se no encontro de maneiras de ler, coletivas ou individuais, herdadas ou inovadoras íntimas ou públicas e de protocolos de leitura depositados no objeto lido, não somente pelo autor que indica a justa compreensão de seu texto, mas também pelo impressor que compõe as formas tipográficas, seja com um objetivo explicito, seja inconscientemente, em conformidade com os hábitos de seu tempo. (CHARTIER, 2001, p. 78).

É interessante considerar que o que está escrito não é apenas uma abordagem descritiva e pura do fato, acontecimento, ou informação em si, mas sim, é o resultado de um estudo que traz as influências de quem o escreve. No entanto, assim como quem escreve deixa seus vestígios, quem lê também o faz, visto que suas impressões, conclusões e formas de compreender influenciam a leitura e o entendimento da mesma.

A escrita é um recurso que pode ser observado como algo que grava, imortaliza a história e as demais produções de que faz parte. Assim:

Efetivamente, a escrita substitui as representações tradicionais que autorizavam o presente por um trabalho representativo que articula num mesmo espaço a ausência e a produção. Na sua forma mais elementar, escrever é construir uma frase percorrendo um lugar supostamente em branco, a página [...] (CERTEAU, 1982, p. 12).

0 que se escreve, torna-se um registro da pesquisa do empírico da vivência, o que preenche o papel são conclusões, lembranças, indagações, problematizações sobre algo que se investiga. No entanto, as frases ali dispostas ligam-se a um ou mais objetos, que a partir de então estarão representados por meio dos escritos. 
A história ocorre por meio da interligação entre os fatores que a determinam, é a relação da ciência com o objeto, como destaca Certeau, (1982, p. 24): “Certamente, em seu uso corrente, o termo história conota, sucessivamente, a ciência e seu objeto - a explicação que se diz e a realidade daquilo que se passou ou se passa [...]”. A história são as coisas; o passar do tempo; os acontecimentos - sejam quais forem e estejam onde estiverem; é um conjunto de fatores que possibilitam um discurso. Como destaca o autor, é a relação constante da ciência com seu objeto, do homem com a vida, com o tempo, com as mudanças e permanências, são as explicações do ontem, mas, também do hoje.

Para Certeau, (1982, p. 70), “a organização da história é relativa a um lugar e a um tempo, o que ocorre, inicialmente, por causa de suas técnicas de produção. Falando em geral, cada sociedade se pensa "historicamente' com os instrumentos que the são próprios”. As sociedades constroem sua história no tempo e no espaço, mas de formas diferentes umas das outras; o passado e o presente de cada cidade, país ou estado se faz com as considerações que seu povo possui, a ideia que fazem de si mesmos, de suas tradições, mudanças e continuidades.

De fato, a escrita histórica - ou historiadora - permanece controlada pelas práticas das quais resulta; bem mais do que isto, ela própria é uma prática social que confere ao seu leitor um lugar bem determinado, redistribuindo o espaço das referências simbólicas e impondo, assim, uma "lição"; ela é didática e magisterial [...]. (CERTEAU, 1982, p. 90).

A escrita, nas palavras do autor traduz o ocorrido, a prática, que, por sua vez influencia aquilo que se escreve. Os escritos interferem na sociedade, pois tem algo a dizer sobre a mesma e é isso que o leitor busca apreender, a leitura fala ao leitor que por sua vez a compreende da sua forma.

Exemplos, de como a leitura interfere no modo de pensar do leitor e na maneira como o mesmo compreende o texto, podem ser encontrados na obra 0 queijo e os vermes na qual Carlo Ginzburg (2006), nos apresenta Menochio, um moleiro que ao ser acusado de cometer heresias passa a ser interrogado pelos tribunais da inquisição. Em sua 'defesa' o personagem deixa claro a interferência daquilo que leu ao longo da vida, de forma que tais leituras acabam direcionando a ideia que faz de Deus, do mundo e da humanidade.

Dentre as coisas que Menochio dizia tentando explicar-se, estavam as argumentações sobre o que pensava de Deus e da religião:

\begin{abstract}
[...] "Conceda-me a graça de me ouvir, senhor. Um grande senhor declarou seu herdeiro aquele que tivesse em certo anel precioso; aproximando-se da morte, mandou fazer outros dois anéis parecidos com o primeiro e, como tinha três filhos, deu a cada um deles um anel. Cada um deles julgava ser o herdeiro e ter o verdadeiro anel, mas, dada a semelhança, não se podia saber ao certo. Do mesmo modo, Deus possui vários filhos que ama, isto é, os cristãos, os turcos, e os judeus, e a todos deu a vontade de viver dentro da própria lei e não se sabe qual seja a melhor. Mas eu disse, tendo nascido cristão, quero continuar cristão e, se tivesse nascido turco, ia querer viver como turco." "O senhor acredita então", insistiu o inquisidor, "que não se saiba qual seja a melhor lei?" Menochio respondeu: "Senhor, eu penso que cada um acha que a sua fé seja a melhor; mas, não se sabe qual é a melhor; mas porque meu avô, meu pai e os meus são cristãos, eu quero continuar cristão, eu quero continuar cristão e acreditar que esta seja a melhor fé”. (GINZBURG, 2006, p. 92).
\end{abstract}

Menochio toma como exemplo a história do senhor que possuía seus herdeiros para falar do seu modo de entender Deus; como alguém que possui filhos diferentes uns dos outros, mas que dá a chance de viverem com suas diferenças, pois não as julga. Para o moleiro Deus seria um pai que não impõe, que apenas ama e compreende.

No entanto, é interessante perceber seu pensamento acerca da religião, dando a ela um caráter cultural, aprendido, tradicional, visto que considera ser cristão porque vem de uma família cristã, mas que poderia ser judeu se seus parentes assim o fossem, pois não existe melhor ou pior fé, correta 
ou errada, existe a fé de cada um, como existe a cultura as tradições e as famílias.

A história relatada para exemplificar sua defesa, foi lida por ele no livro Cento novelle, de Boccaccio (GINZBURG, 2006, p. 93), e faz com que o autor chame a atenção para a maneira como Menochio compreende o que lê. Ginzburg (2006, p. 93) escreve:

Tudo o que vimos até agora demonstra que Menochio não reproduzia simplesmente opiniões e teses de outros. Seu modo de lidar com os livros, suas afirmações deformadas e trabalhosas são sem dúvida sinais de uma reelaboração original. É evidente que esta não partia do nada.

O personagem não se apropriava das ideias que encontrava nas obras, estas eram para ele um auxilio para sua compreensão, ele as reelaborava, problematizava, e fazia uma analogia com a realidade e com o entendimento que possuía das coisas. 0 que era lido não permanecia tal e qual estava nos livros, mas era transformado por seu modo de entender, e pensar.

Existem, portanto, modos de ler. A leitura pode ser silenciosa, muito comum no campo acadêmico atual, pode ser também oralizada, quando une a leitura com a comunicação do que se lê, no entanto a leitura silenciosa é fruto de um processo, onde nos séculos IX-XI, os monges deixaram de ler e copiar utilizando a fala, e em decorrência disso no século XIII, ocorre a difusão da leitura em silêncio nas universidades. Assim o ler em voz alta se torna um procedimento pouco usado, a leitura silenciosa adota uma postura mais analítica, neste contexto (CHARTIER, 2001, p. 82).

Para Goulemot (2001, p. 107-108) “a leitura é sempre produção de sentido." Para o autor, "[...] ler é, constituir e não reconstituir um sentido". Assim, cada leitor dará um significado particular e terá um entendimento próprio acerca do que lê. A percepção que se tem com relação às leituras, não é única, pois, a cada novo leitor nascem novos sentidos, novos significados.
[...] Quer dizer que cada época constitui seus modelos e seus códigos narrativos e que no interior de cada momento existem códigos diversos, segundo os grupos culturais. [...] Portanto, deve-se reconhecer que diversos modos de narrativa coabitam no mesmo espaço cultural e social. A posse dos códigos que os regem permite a leitura [...]. (GOULEMOT, 2001 p. 113).

Assim, as produções de uma época estão envolvidas pelos aspectos sociais do período, estas características que estão fortemente ligadas à cultura influenciam a escrita e a composição das obras, e também as formas de leitura e entendimento das obras, por parte do leitor.

[...] ler é fazer-se ler e dar-se a ler. Em outros termos dar um sentido é falar sobre o que, talvez não se chegue a dizer de outro modo e mais claramente. Portanto seria permitir uma emergência daquilo que está escondido [...]. A cada leitura, o que já foi lido muda de sentido, torna-se outro. É uma forma de troca [...]. (GOULEMOT, 2001, p. 116).

Desta forma, a leitura é uma troca tanto do livro para com o leitor como do leitor para com a obra, pois, os escritos irão trazer muitas informações a serem absorvidas pelo leitor, no entanto o mesmo ao interpretar as informações da sua maneira, proporciona uma troca e ao mesmo tempo um aprendizado diferente acerca da mensagem que a obra quer transmitir. É importante ressaltar que cada vez que se lê algo, lê-se com outros olhos, com outras perspectivas, o que permite outras conclusões.

A leitura de um livro didático é um bom exemplo da leitura particular que cada leitor possui quando lê algo. Um aluno ao ler o livro entende as informações como certo aspecto de descoberta mantendo-se concentrado nos acontecimentos em si, nas datas, nos comportamentos, nas culturas explícitas no texto, enfim, no conteúdo em si.

No entanto, a compreensão acerca do mesmo, quando a leitura é feita por alguém que pesquisa livros didáticos ou que trabalha e os tem como ins- 
trumento de trabalho, é diferenciada. O professor, ou o pesquisador fará uma leitura "nas entrelinhas", possuindo uma reflexão que vai além dos conteúdos como fatos, como fonte de aprendizado. Neste contexto o pensamento crítico é adotado e surgem novas indagações e problemáticas que despertam outros sujeitos misturados aos personagens que a história imortalizou naquelas páginas.

\section{ABORDANDO O LIVRO DIDÁTICO}

As fontes identificadas para pensar a representação dos indígenas foram cinco livros didáticos utilizados nas escolas, por estudantes das séries iniciais. Estes livros servem como material de apoio para as aulas, e foram fornecidos pelo governo estadual, e repassados às escolas municipais de Irati.

Os livros didáticos utilizados neste estudo foram emprestados da Secretaria de Educação Municipal, a qual possui em seu arquivo algumas obras, tendo concedido parte delas para a análise que proporciona a construção desta reflexão.

Os livros considerados para a reflexão são: Criar e aprender: um projeto pedagógico: História do Paraná (CUNHA; FRESSATO, 2008), Aventura do aprender: suplemento do Paraná: história, geografia (GIL, 2000), O Paraná de todas as cores (SILVA, 2001), História do Paraná (ROLLEMBERG, 2008) e Historiando o Paraná - Recortes de tempos e vivências (BARROS, PIZZATO; MARQUES, 2011).

Todas as obras possuem como enfoque a História do Paraná, sendo que algumas unem a história e a geografia. As mesmas são destinadas ao $4^{\circ}$ e $5^{\circ}$ ano das séries iniciais de ensino.

O livro História do Paraná de Graziella Rollemberg (2008) focado no ensino dos alunos do $4^{\circ}$ ou $5^{\circ}$ ano, é composto de 152 páginas. 0 livro possui uma escrita fluída, formulada de uma maneira interessante, pois, procura fazer uma reflexão acerca do tempo, utilizando-se de parlendas e de relógios para auxiliar na compreensão. É importante abordar o aspecto temporal com os alunos, porque além de ser um componente curricular, permite o entendimento do passado e sua relação com a construção dos fatos. Por meio da discussão acerca do tempo, é realizada a abordagem da mudança e permanência, para em seguida, tratar do que é a História. Busca mostrar ao aluno que ele também tem história, por meio do estudo das tradições populares e da cultura.

Quando se refere à história do Paraná, e a questão indígena neste Estado, o livro cita a existência de três diferentes etnias indígenas: Kaingang, Guarani e Xetá, A autora relaciona o indígena ontem e hoje, destacando que atualmente vivem em reservas. Faz-se uma explicação a cerca das três etnias, apresentando sempre algumas gravuras de acordo com o que é abordado. No entanto, o conteúdo é apresentado de forma bastante resumida, contendo poucas fontes e desenvolvido a partir de depoimentos.

Já o livro O Paraná de todas as Cores (SILVA, 2001) apresenta logo no início a temática indígena, destacando que os portugueses não "descobriram" o Brasil, mas sim que aqui viviam muitas populações indígenas anteriores a 1500. Na sequência, abordam-se os indígenas no Paraná, destacando as três etnias existentes: Kaingang, Guarani e Xetá. Esse livro é mais completo, no que diz respeito à abordagem do modo de vida destes povos, antes da colonização. 0 livro enfatiza cada etnia separadamente, destacando os aspectos culturais de cada um, como: a moradia o trabalho e algumas curiosidades sobre sua cultura.

Contudo, embora seja mais completo em sua abordagem quanto ao passado e a cultura das etnias indígenas paranaenses, quando se refere, a atualidade o material, poderia tratar o tema com maior ênfase e enriquecer o debate com mais dados, ainda que apresente a condição dos indígenas nos dias de hoje, 
Em outro livro que trata do tema, intitulado Aventura do aprender: suplemento do Paraná: história, geografia (GIL, 2000), é bastante conciso, possuindo apenas 48 páginas. Sobre os indígenas, o livro apresenta apenas uma página bastante resumida, onde são citadas as três etnias indígenas encontradas no Paraná, o material não menciona os povos na atualidade.

Já o livro Criar e aprender: um projeto pedagógico: História do Paraná, (CUNHA; FRESSATO, 2008) assim como os anteriores, apresenta uma reflexão sobre os indígenas que habitavam e habitam o Paraná, o que é representado de uma forma bem resumida. 0 livro aborda, ainda, a relação dos indígenas com a religião católica, referindo-se a província jesuítica do Guairá, e posteriormente fala do final das reduções paranaenses. No que segue, faz-se uma discussão sobre a condição dos indígenas paranaenses na atualidade, de forma bastante resumida, abordando as questões destes povos nos dias de hoje, como as lutas pela delimitação de seus territórios.

No livro Historiando o Paraná - Recortes de tempos e vivências (BARROS, PIZZATO; MARQUES, 2011), encontra-se logo no início as reflexões que pretende discorrer sobre a construção da identidade paranaense. A temática indígena começa a ser explicada, quando é abordado o descobrimento do Brasil, com o título: "Quem estava e quem chegou no Paraná" (BARROS, PIZZATO; MARQUES, 2011, p. 26), em que os autores explicam que nas terras onde hoje é o estado encontravam-se indígenas, destacando as diversas etnias existentes, o modo de vida e a cultura dos nativos que divergia dos modos culturais europeus.0 livro apresenta, ainda que de forma resumida, alguns aspectos culturais, relacionados a agricultura (tarefa das mulheres), a caça, a pesca e a construção de casas (tarefas masculinas), ressaltando o uso comum das coisas, inclusive da terra.

É interessante destacar o momento em que o livro aborda a criança indígena, levando em consideração que nas tribos as mesmas aprendiam por meio da experiência, ouvindo e vendo. Posteriormente, pode ser encontrado um texto onde se fala do habitat de um menino indígena, de seu cotidiano, como o fato do menino acompanhar o pai nas caças, o manuseio de arco e flecha sua alimentação e brincadeiras.

Em seguida, o conteúdo do livro caminha para as influências das diferentes culturas na formação da sociedade paranaense, tratando da contribuição indígena na alimentação com a mandioca, por exemplo. Aborda, ainda, a questão da escravidão, na qual tais povos trabalhavam com a mineração e lavouras, e destaca a miscigenação ocorrida entre portugueses e índias, que é apresentada de forma harmônica e pacífica, com o termo: "lares mistos" (BARROS, PIZZATO; MARQUES, 2011, p. 38). O livro apresenta a troca cultural entre europeus e indígenas, que ambos aprenderam um com o outro. Fala do indígena hoje, que não vive mais na selva, e fala a língua do colonizador, que resiste, luta por seu espaço, pelo respeito, por seus direitos.

O material cita temas que poderiam ser desenvolvidos e que certamente enriqueceriam muito o conteúdo, como por exemplo, os rituais de passagem, os mitos que são transmitidos oralmente pelas pessoas idosas, e as festas.

\section{CONSIDERAÇÕES FINAIS}

Desta forma, percebe-se que embora os conteúdos apresentados nos livros didáticos sejam semelhantes, diferem nas formas de abordagem, alguns são mais completos, outros não; alguns priorizam o passado, outros conseguem abordar passado e presente.

Considerando esta breve reflexão sobre os livros didáticos como fontes de reflexão para a representação dos indígenas na sociedade brasileira, torna-se iminente o aprofundamento das reflexões a respeito de como e do que os alunos estão aprendendo sobre a formação da sociedade paranaense e sua composição social. 
É mister Investigar a forma com que os indígenas foram abordados nos livros do ensino fundamental de História do Paraná, com o intuito de destacar a importância do estudo das populações indígenas e suas culturas, para a sua compreensão e alargamento do debate ao relacionado ao preconceito, ainda muito frequente.

Cabe aos professores rever a ideia constantemente representada de indígena com cocar, arco e flecha, destacando a existência de um indígena contemporâneo, que com o passar dos tempos acompanhou as transformações culturais e caracteriza-se hoje como um indivíduo extremamente ativo e politizado em nossa sociedade.

Entender a presença dos indígenas nos livros didáticos e refletir sobre/e com ela, então, significa abordar o indígena enquanto parte integrante da sociedade, o que possui seu trabalho, seus comportamentos específicos, sua cultura, seu direito à diferença, enfim, seu direito de integrar a diversidade.

\section{REFERÊNCIAS}

BARROS, Darci Alda; PIZZATO, Maria Dilonê; MARQUES, Marlene. Historiando o Paraná: recortes de tempos e vivências, $4^{\circ}$ ou $5^{\circ}$ ano. 2.ed. Curitiba: Base editorial, 2011. 192p.

CAVALHEIRO, Rosa Maria; COSTA, Flamarion Laba da. A temática indígena no livro didático. Disponível em: <http://www.diaadiaeducacao.pr.gov.br/portals/pde/ arquivos/730-4.pdf>. Acesso em: 24 set. 2012.

CERTEAU, Michel de. A escrita da História, trad. Maria de Lourdes Menezes, Rio de Janeiro: Forense Universitária, 1982.

CHARTIER, Roger. Práticas da leitura. São Paulo: Estação Liberdade, 2001.
CUNHA, Fernando; FRESSATO, Soleni Terezinha Biscouto. Criar e aprender: um projeto pedagógico: História do Paraná, $5^{\circ}$ ano. São Paulo: FTD, 2008. 144p.

GIL, Ana Helena C. de Freitas; VALOTO, Ana Maria. Aventura do aprender: suplemento do Paraná: história, geografia, $1^{\circ}$ ao $4^{\circ}$ bimestre. Curitiba: Base, 2000. 48p.

GINZBURG, Carlo. 0 queijo e os vermes: o cotidiano e as ideias de um moleiro perseguido pela inquisição, trad. Maria Betânia Amoroso. São Paulo: Companhia das letras, 2006.

GOULEMOT, Jean-Marie. Da leitura como produção de sentidos. In: CHARTIER, Roger (org.). Práticas da leitura. São Paulo: Estação Liberdade, 2001.

GRUPIONI, Luís Donisete Benzi. Índios: passado, presente e futuro. In: Secretaria de educação à distância, Secretaria de educação fundamental. Cadernos da TV escola Îndios do Brasil 1. Brasília, 2001.

MARCOS, Maria Cândida. Repensar a temática indígena nos livros didáticos: Críticas e desafios. Disponível em: <http://www.indioeduca.org/wp-content/ uploads/2011/10>. Acesso em: 21 set. 2012.

MARIANO, Nayana Rodrigues Cordeiro. A representação sobre os índios nos livros didáticos de História do Brasil. Disponível em: <http://www.ce.ufpb.br/ppge/ Dissertacoes/dissert06/Nayana\%20Rodrigues/A\%20 REPRESENTA\%C $7 \%$ C 30\%20SOBRE\%200S\%20 \%CDNDIOS.pdf>. Acesso em: 24 set. 2012.

MARTINS, Maria Cristina Bohn. As sociedades indígenas, a história e a escola. Antíteses, v.2, n.3, jan.-jun. 2009. p.153-167. Disponível em: http://www.uel.br/ revistas/uel/index.php/antiteses/article/view/2419. Acesso em 20 set. 2012.

MOTA, Lucio Tadeu; RODRIGUES, Isabel Cristina. A questão indígena no livro didático "Toda a história”. Hist. En- 
sino, Londrina, v.5, out. 1999. p.41-59. Disponível em: <http://www.uel.br/revistas/uel/index.php/histensino/ article/view/12435>. Acesso em 26 set. 2012.

ROLLEMBERG, Graziella. História do Paraná, $4^{\circ}$ ou $5^{\circ}$ ano. São Paulo: Ática, 2008. 152p.

SILVA, Sérgio Aguilar et al. O Paraná de todas as cores: história do estado do Paraná para o Ensino Fundamental. Curitiba: Base, 2001. 144p.

Recebido em: 16 de Dezembro de 2014 Avaliado em: 27 de Janeiro de 2015 Aceito em: 20 de Março de 2015
1. Especialista em Educação e Diversidade - Universidade Estadual do Centro-Oeste (UNICENTRO - PR), campus de Irati-PR. E-mail: mkullerb@yahoo.com.br 2. Professor Doutor. Departamento de História - Universidade Estadual do Centro-Oeste (UNICENTRO - PR), campus de Irati - PR. Professor do Programa de Pós-graduação em História - Universidade Estadual do Centro-Oeste (UNICENTRO - PR). Email: oseias50@yahoo.com.br 